\title{
Etiologies of Neonatal Mortality in a Tertiary Care Hospital in a Resource-Limited Setting
}

\author{
Calixte Ida Penda ${ }^{1,2,3^{*}}$ (D) Ritha Mbono Betoko ${ }^{1,2}$, Danielle Kedy Koum ${ }^{1,4}$, Essome Henri ${ }^{5,6}$, \\ Patricia Epée Eboumbou ${ }^{1,7}$, Christelle Mpah Edimo², Eyoum Billè Bertrand ${ }^{2,8}$, \\ Charlotte Eposse ${ }^{1,2}$, Olivier Koki Ndombo 9,10
}

\author{
${ }^{1}$ Department of Clinical Sciences, Faculty of Medicine and Pharmaceutical Sciences, University of Douala, Douala, Cameroon \\ ${ }^{2}$ Department of Pediatrics, Laquintinie Hospital, Douala, Cameroon \\ ${ }^{3}$ General Hospital of Douala, Douala, Cameroon \\ ${ }^{4}$ Déido District Hospital, Douala, Cameroon \\ ${ }^{5}$ Department of Surgery, Faculty of Medicine and Pharmaceutical Sciences, University of Douala, Douala, Cameroon \\ ${ }^{6}$ Department of Gynecology, Laquintinie Hospital, Douala, Cameroon \\ ${ }^{7}$ Bonassama District Hospital, Douala, Cameroon \\ ${ }^{8}$ Faculty of Sciences, University of Dschang, Dschang, Cameroon \\ ${ }^{9}$ Department of Pediatrics, Faculty of Medicine and Biomedical Sciences, University of Yaoundé 1, Yaoundé, Cameroon \\ ${ }^{10}$ Chantal Biya Foundation, Mother-Child Centre, Yaoundé, Cameroon \\ Email: ${ }^{\star}$ Calix.penda@gmail.com
}

How to cite this paper: Penda, C.I., Betoko, R.M., Koum, D.K., Henri, E., Eboumbou, P.E., Edimo, C.M., Bertrand, E.B. Eposse, C. and Ndombo, O.K. (2021) Etiologies of Neonatal Mortality in a Tertiary Care Hospital in a Resource-Limited Setting. Open Journal of Pediatrics, 11, 268-280. https://doi.org/10.4236/ojped.2021.112026

Received: April 29, 2021

Accepted: June 5, 2021

Published: June 8, 2021

Copyright $\odot 2021$ by author(s) and Scientific Research Publishing Inc. This work is licensed under the Creative Commons Attribution International License (CC BY 4.0).

http://creativecommons.org/licenses/by/4.0/

\section{Open Access}

\begin{abstract}
Background: Neonatal mortality remains a major public health problem in low income countries. The survival within the first 28 days of life remains a challenge in such countries. Many strategies have been implemented to reduce deaths in children under five especially in sub-Saharan Africa. Laquintinie Douala Hospital benefits from some of these measures including a perinatal network and an emergency voucher. We aimed to describe the main causes of neonatal deaths at Laquintinie Douala Hospital. Methods: We carried out a cross-sectional study including files of all deceased neonates in the neonatal unit during a 24 months period from January $1^{\text {st }}, 2017$ to December $31^{\text {st }}, 2018$. Data collection included socio-demographic characteristics of the mothers and the newborns, clinical and therapeutic data and the evolution of the newborn. We used SPSS 20 software for data analysis with a $p$-value less than 0.05 . Results: We included 270 files with an overall mortality rate of $13.1 \%$ and a sex ratio of 1.2. The main causes of death included prematurity (37.8\%), neonatal infection (34.1\%) and neonatal asphyxia (24.4\%). The main factors associated with deaths included informal sector $(O R=5.49 ; 95 \% C I$ 0.86 - 34.77; $p=0.07)$ and a primary level of education for mothers, malaria during pregnancy $(O R 2.28 ; 95 \% C I, 1.44-3.12 ; p=0.0001)$, very preterm babies $(O R 6.45$; 95\% $C I 4.68-8.89 ; p<0.001)$ and resuscitation $(O R$ 1.63;
\end{abstract}


95\% CI $1.25-2.13 ; p=0.0001)$. Conclusion: Neonatal mortality was lower than data in previous studies but remains high. This highlights the need for caregiver training and improvement of antenatal visits in our setting.

\section{Keywords}

Newborn, Neonatal Mortality, Laquintinie Douala Hospital, Cameroon

\section{Introduction}

Neonatal mortality remains a major public health problem in low-income countries. In 2016, 2.6 million children died before their $28^{\text {th }}$ day of life. Every day, almost 7000 newborns die [1]. They represent almost half of the deaths recorded in under five years children. The majority of these deaths occur in lowest-middle income countries, especially in sub-Saharan Africa and Southern Asia [1]. Neonatal mortality reflects the quality of care provided to pregnant women and newborns during the first days of life [2]. In order to achieve the fourth Millennium Goal for sustainable development, strategies have been implemented in Sub-Saharan Africa to reduce neonatal mortality [3]. Programs such as the Expanded Immunization Program, high-quality antenatal care, and integrated management of childhood illnesses as well as emergency obstetrical and neonatal care have been implemented.

Despite these strategies, the neonatal mortality rate remains high in sub-Saharan Africa. It was estimated at 35.7/1000 in Mali, 42.3/1000 in the Central African Republic and 36.6/1000 in Ivory Coast in 2016 according to UNICEF [4]. In Cameroon, the neonatal mortality rate was estimated at 28 per 1000 live births in 2015 [5]. Hospital-based studies respectively found 20.3\% of deaths in 2015 at the Laquintinie Douala Hospital (LDH) and $15.7 \%$ of deaths at the Bamenda Regional Hospital in 2017 [6] [7].

Due to the burden of neonatal mortality at LDH in 2015, some cost-effective interventions were initiated to improve survival of newborns in neonatal care unit. A perinatal referral network was created for management of critically ill neonates. They also set up an emergency care voucher with recovery of deferred costs. The perinatal network was created on August 17, 2016. It is managed by 3 administrators. A team of 112 maternal and child caregivers is involved. They are posted in public and private health facilities in Douala and neighboring towns. Communication is established through a social network. Each caregiver gives key data for adequate referral destinations and rapid admission of critically ill newborns. Between 10 and 20 communications are recorded every day. Recovery of deferred cost is a tool that improves management of emergencies for newborns with no financial support. The aim of this study was to evaluate the impact of these new strategies in the care of newborns through the study of neonatal deaths. Specifically, we aimed to estimate the in-hospital neonatal mor- 
tality rate, identify the leading causes and associated factors in this referral hospital.

\section{Methods}

\subsection{Study Design and Setting}

We retrospectively recorded files of newborns admitted and deceased during a 24 months' period from January $1^{\text {st }}, 2017$ to December $31^{\text {st }}, 2018$ in the neonatal unit of Laquintinie Douala Hospital. It is a teaching hospital located in the Littoral region, in the economic capital of Cameroon. It is a tertiary care health facility. The neonatal unit is divided into 3 areas (red area or emergency room, orange area for referred newborns and green area for newborns coming from the hospital maternity ward). It has a capacity of 38 places including 28 beds, 7 incubators and 3 neonatal resuscitation tables. It has a reception ward, an intensive care unit and a kangaroo care unit for premature babies. The medical team is made up of 3 pediatricians and 4 general practitioners. The nursing team is made up of 25 nurses divided into 4 teams.

Some strategies like the perinatal network and emergency care voucher had improved management of neonatal emergencies. The perinatal network is a team of 112 maternal and child caregivers who are posted in public and private health facilities in Douala and neighboring towns. Communication is established through a social network. Each caregiver gives key data for adequate referral destinations and rapid admission of critically ill newborns. It helps to increase survival of neonates in vital distress. Moreover, they benefit from the emergency care voucher (called the green voucher) for drugs and emergency exams with deferred cost recovery.

\subsection{Study Population}

We included records of all newborns who arrived alive and who died during hospitalization in the neonatology unit of the Laquintinie Douala Hospital. Records of newborns were included consecutively. Records of newborns who arrived deceased and those with incomplete records were excluded (Figure 1).

\subsection{Data Collection}

We collected data from neonatal unit registers and medical records. Data collection was performed with a pretested record and variables included:

- The socio-demographic characteristics of the mother (age, profession, level of education) and the newborn (age, gender, birth weight, place of origin, means of transport);

- Obstetrical data (parity, gestational age, number of antenatal consultations, tetanus/antianemic/antimalarial prophylaxis, serologies performed, risk factors for neonatal sepsis, place and route of delivery, apgar score);

- The clinical characteristics of newborns (reason for admission, clinical signs, positive diagnosis, duration of treatment, time of death). 


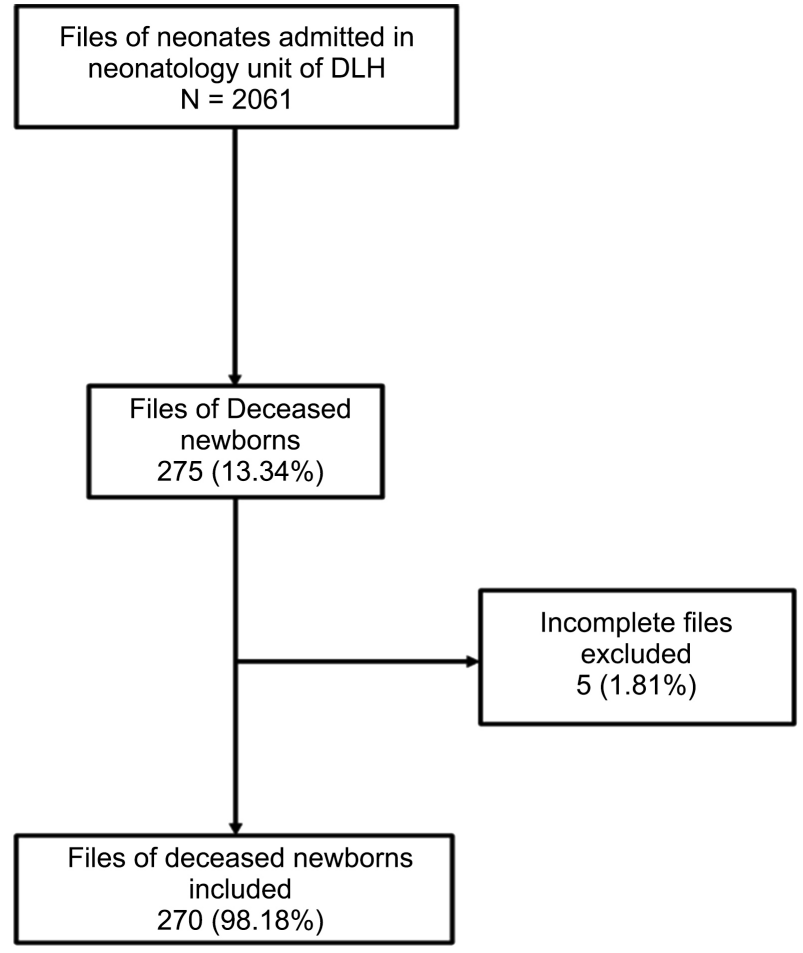

Figure 1. Flow chart of files included during the study period.

\subsection{Definition of Terms}

Neonatal mortality was defined as death that occurred within the first 28 days of life. Neonatal sepsis was considered for any newborn with infectious risk factors (prolonged rupture of membranes, per partum fever, urogenital infection in the third trimester, chorioamnionitis), clinical signs of infection (fever, hypothermia, jaundice, respiratory distress, seizures, refusal to breastfeed, pallor) and biological criteria (CRP greater than $20 \mathrm{mg} / \mathrm{l}$, with or without bacteriological or radiological evidence of infection). Respiratory distress was considered for a Silverman score greater than $2 / 10$. Neonatal asphyxia was defined as inability to establish a cry or autonomic breathing at birth with an alteration of the Sarnat score without any other identifiable etiologies. It should be noted that there was no gas measurement to measure blood $\mathrm{pH}$ and base deficiency. A poor Apgar score was defined as an Apgar score less than 7 at the $5^{\text {th }}$ minute. Small for gestational age (SGA) was defined as a birth weight less than $2500 \mathrm{~g}$. Prematurity was defined as a gestational age less than 37 weeks' amenorrhea.

\subsection{Statistical Analysis}

The data were recorded using EPI-INFO software version 7.2.0. We used SPSS software version 20.0 (IBM Corporation, Chicago, USA) for statistical analysis. Continuous variables were expressed as median with the interquartile range. Categorical variables were presented as proportions, percentages or frequencies. We used the Chi square test to compare proportions between groups. Quantitative variables were compared using student's t test. We used a logistic regression 
to identify factors associated with neonatal mortality. A $p$-value $<0.05$ was considered statistically significant.

\subsection{Ethical Considerations}

This study received ethical approval from the institutional board review of the Faculty of Medicine and Pharmaceutical Sciences of Douala ( ${ }^{\circ} 1760$ CEI-Udo/ 04/2019/T). Administrative approval was obtained from the head office of the Laquintinie Hospital in Douala ( ${ }^{\circ}$ 03795/AR/MINSANTE/DHL/CM). The principles of anonymity and confidentiality were respected in reporting the results.

\section{Results}

\subsection{Neonatal Mortality Rate}

During the study period, 2061 newborns were admitted to the neonatal unit of LDH. Among them, 275 newborns died, for an overall neonatal hospital mortality rate of $13.3 \%$. We excluded 5 files due to missing data. We retained 270 files (Figure 1).

\subsection{Characteristics of Deceased Newborns}

In total, $77 \%$ of deceased newborns were admitted on the first day of life. Out of the deceased newborns, 149 (55.2\%) were male and the sex ratio was 1.2. According to the place of delivery, $173(64.1 \%)$ newborns were delivered at Laquintinie Douala Hospital and 80 (29.6\%) newborns were coming from another health facility in the town. More than half of deceased newborns were transported by families prior to admission (Table 1 ).

A total of $263(97.4 \%)$ deceased newborns were born in a maternity. Vaginal delivery was effective in 205 (75.9\%) cases. Cesarean section had been performed for $65(24.1 \%)$ newborns. The main indications for cesarean section were acute fetal distress (27.7\%) severe pre-eclampsia (23.2\%) and cephalo-pelvic disproportions (12.3\%). The median weight (IQR) of newborns at birth was 2052 (1347 - 3200) grams with a range of $700 \mathrm{~g}$ to $4800 \mathrm{~g}$. More than half of the newborns who died were born prematurely. The median Apgar scores were 6 (5 - 8) at the 1st minute and $7(6-9)$ at the $5^{\text {th }}$ minute, respectively. Resuscitation was performed in 104 newborns (38.51\%).

The median age of mothers (IQR) was 28 (22.7 - 31) years with a range of 17 to 43 years. The 25 - 29 age group represented $34.1 \%$ of mothers, followed by the 20 - 24 age group (30.4\%). Mothers working in the informal sector represented $60.4 \%$, followed by pupils and students $(26.3 \%)$. More than half of the mothers $(\mathrm{n}=204)$ had made less than 4 antenatal consultations during their pregnancy (Table 2). They received two doses of tetanus toxoid vaccine. Antimalarial and anti-anemic prophylaxis had been observed in most mothers. All mothers were tested for HIV and 12 (4.4\%) were positive. Of the 270 mothers, 21 (8.1\%) had per partum fever and $150(44.4 \%)$ had premature rupture of membranes within 6 hours. 
Table 1. Baseline characteristics of the dead newborns.

\begin{tabular}{|c|c|}
\hline Variables & $\mathrm{N}(\%)$ \\
\hline \multicolumn{2}{|l|}{ Age (days) } \\
\hline$<1$ & $200(74.0)$ \\
\hline $1-7$ & $43(16.0)$ \\
\hline$>7$ & $27(10.0)$ \\
\hline \multicolumn{2}{|l|}{ Gender } \\
\hline Male & $149(55.2)$ \\
\hline Female & $121(44.8)$ \\
\hline \multicolumn{2}{|c|}{ Birth weight (grams) } \\
\hline$<2500$ & $158(58.6)$ \\
\hline$>2500$ & $112(41.4)$ \\
\hline \multicolumn{2}{|c|}{ Gestational age (weeks) } \\
\hline $28-32$ & $98(36.3)$ \\
\hline $32-36$ & $64(23.7)$ \\
\hline $37-42$ & $93(34.4)$ \\
\hline$>42$ & $15(5.6)$ \\
\hline \multicolumn{2}{|l|}{ Provenance } \\
\hline Referred & $80(29.6)$ \\
\hline Home & $17(6.3)$ \\
\hline LHD ${ }^{*}$ Maternity & $173(64.1)$ \\
\hline \multicolumn{2}{|l|}{ Mean of transport } \\
\hline Non-medical & $193(71.5)$ \\
\hline Medical & $77(28.5)$ \\
\hline
\end{tabular}

\subsection{Features of Mothers of Deceased Newborns}

The median age of mothers (IQR) was $28(22.7$ - 31) years with a range of 17 to 43 years. The 25 - 29 age group represented $34.1 \%$ of mothers, followed by the 20 - 24 age group (30.4\%).

Mothers working in the informal sector represented $60.4 \%$, followed by pupils and students $(26.3 \%)$. More than half of the mothers $(n=204)$ had made less than 4 antenatal consultations during their pregnancy (Table 2). They had received two doses of tetanus toxoid vaccine. Antimalarial and anti-anemic prophylaxis had been observed in most mothers. All mothers were tested for HIV and 12 (4.4\%) were positive. Of the 270 mothers, 21 (8.1\%) had per partum fever and $150(44.4 \%)$ had premature rupture of membranes within 6 hours. 
Table 2. Baseline characteristics of the mothers with dead newborns.

\begin{tabular}{|c|c|}
\hline Variables & $\mathrm{n}(\%)$ \\
\hline \multicolumn{2}{|l|}{ Age (years) } \\
\hline$<20$ & $12(4.4)$ \\
\hline $20-24$ & $82(30.4)$ \\
\hline $25-29$ & $92(34.1)$ \\
\hline $30-34$ & $60(22.2)$ \\
\hline$>34$ & $24(8.9)$ \\
\hline \multicolumn{2}{|l|}{ Occupation } \\
\hline Student & $71(26.3)$ \\
\hline Formal worker & $23(8.5)$ \\
\hline Informal worker & $176(65.2)$ \\
\hline \multicolumn{2}{|l|}{ Level of education } \\
\hline Primary & $22(8.2)$ \\
\hline Secondary & $177(65.5)$ \\
\hline University & $71(26.3)$ \\
\hline \multicolumn{2}{|l|}{ Parity } \\
\hline Primiparity & $146(54.1)$ \\
\hline Multiparity & $124(45.9)$ \\
\hline \multicolumn{2}{|l|}{ Number of antenatal visits } \\
\hline$<4$ & $205(75.9)$ \\
\hline$>4$ & $65(24.1)$ \\
\hline \multicolumn{2}{|l|}{ Place of delivery } \\
\hline Maternity & $263(97.4)$ \\
\hline At home & $7(2.6)$ \\
\hline \multicolumn{2}{|l|}{ Mode of child birth } \\
\hline Spontaneous vaginal delivery & $205(76.0)$ \\
\hline Cesarean section & $65(24.0)$ \\
\hline
\end{tabular}

\subsection{Clinical Features of Deceased Newborns}

Prematurity, poor Apgar score and acute fetal distress were the main reasons of admission in neonatal unit (Table 3). According to vital parameters, 148 (55.4\%) deceased newborns had hypothermia on admission, 102 (38.2\%) had normal temperature and $17(6.4 \%)$ had fever. The median heart rate (IQR) was 138 (126 - 150) beats/minute. The median respiratory rate (IQR) was 45 (35 - 54) cycles/minute. More than half of the deceased newborns (72.6\%) had an oxygen saturation greater than $95 \%$. 
Table 3. Reason for admission to the neonatal unit.

\begin{tabular}{cc}
\hline Reason for admission & $\mathrm{n}(\%)$ \\
\hline Prematurity & $124(45.9)$ \\
Poor APGAR score & $39(14.4)$ \\
Acute fetal distress & $24(8.9)$ \\
Refusal to suck & $25(9.3)$ \\
Respiratory distress & $17(7.0)$ \\
Fever & $11(4.1)$ \\
Others & $30(11.1)$ \\
Total & $270(100)$ \\
\hline
\end{tabular}

Others*: Jaundice, convulsions, small-for-gestational-age, prolonged rupture of membranes, cough, vomiting.

The newborns showed several signs of severity at the same time. Cyanosis and desaturation were found in $175(64.8 \%)$ and 179 (66.3\%) newborns, respectively. Only 15 (5.6\%) newborns had fever.

\subsection{Etiologies of Neonatal Deaths}

The main causes of neonatal death were prematurity $(\mathrm{n}=102 ; 37.8 \%)$, neonatal sepsis $(n=92 ; 34.1 \%)$ and neonatal asphyxia $(n=66 ; 24.4 \%)$ (Figure 2$)$.

\subsection{The Delay in the Occurrence of Newborn Deaths}

More than half of the newborns $(\mathrm{n}=168 ; 62.2 \%)$ died at night (between 5 p.m. and 7 a.m.). More than 2/5 newborn deaths occurred between 24 and 72 hours after their admission to the neonatal department respectively in 2017 (40.4\%) and (41.4\%) 2018.

\subsection{Factors Associated with Neonatal Mortality}

Newborns whose mothers were in the informal sector [ $O R=5.49 ; 95 \% C I 0.86$ 34.77; $p=0.07]$ and a primary level of education $[O R=2.42$; $95 \% C I 1.98-2.85$; $p=0.0001]$ had a significantly elevated risk of death.

As for obstetrical data, multiparity $[O R=2.61 ; 95 \% C I 0.51-13.19 ; p=$ $0.001]$, a number of antenatal consultations less than $4[O R=3.29 ; 95 \% C I 0.80$ 13.56; $p=0.09]$ and malaria during pregnancy $[O R=2.28 ; 95 \% C I 1.44-3.12 ; p$ $=0.0001]$ increased the risk of neonatal death.

Delivery by cesarean section $[O R 0.59 ; 95 \% C I 0.43-0.82 ; p=0.0001]$ was a protective factor. However, resuscitation $[O R$ 1.63; 95\% CI 1.25 - 2.13; $p=$ $0.0001]$ and extreme prematurity [OR 6.45; 95\% CI 4.68 - 8.89; $p<0.001]$ significantly increased the risk of death as reported in Table 4. 


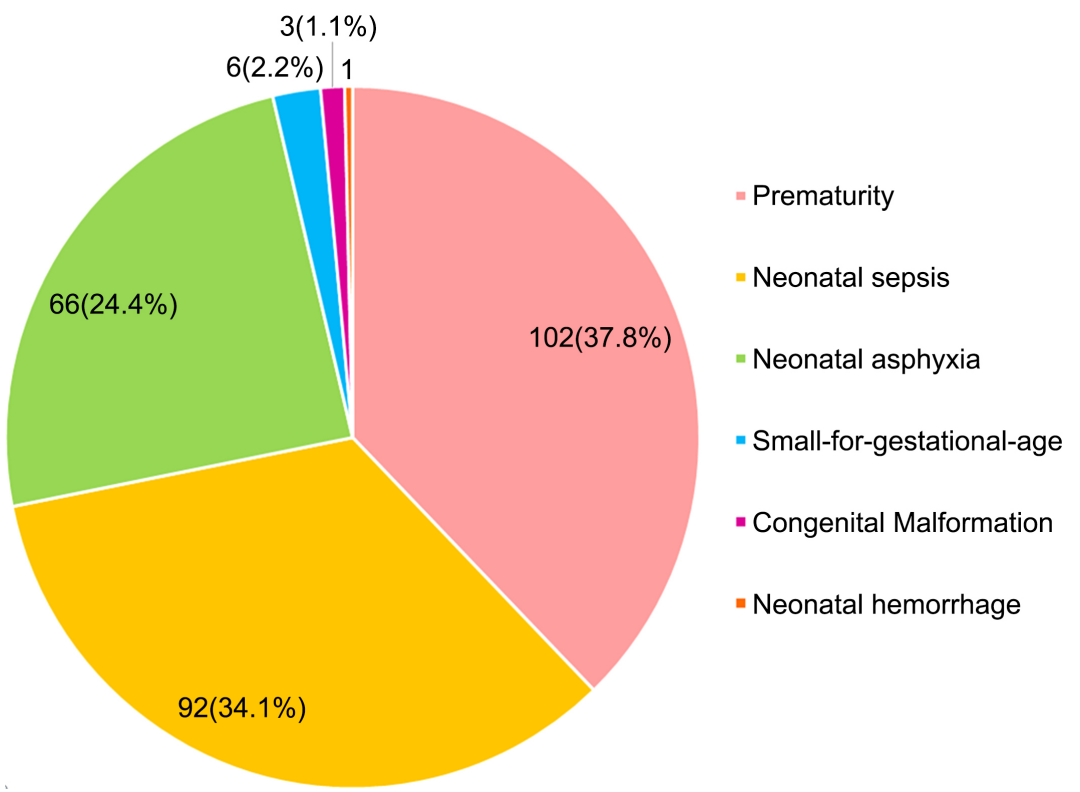

Figure 2. Etiologies of neonatal deaths.

Table 4. Neonatal factors associated to neonatal mortality.

\begin{tabular}{|c|c|c|c|c|}
\hline Variable & Frequencies & Deaths \% & OR (IC à 95\%) & $P$ value \\
\hline \multicolumn{5}{|l|}{ Birth weight } \\
\hline$<2500$ & 158 & 58.6 & $0.31(0.24-0.40)$ & $<0.001$ \\
\hline$>2500$ & 112 & 41.4 & Reference & \\
\hline \multicolumn{5}{|l|}{ Gestational age (weeks) } \\
\hline $28-32$ & 98 & 36.3 & $6.45(4.68-8.89)$ & $<0.001$ \\
\hline $32-36$ & 64 & 23.7 & $3.57(2.52-5.06)$ & $<0.001$ \\
\hline$>42$ & 15 & 5.6 & $2.56(1.44-4.56)$ & 0.001 \\
\hline $37-42$ & 93 & 34.4 & Reference & \\
\hline \multicolumn{5}{|l|}{ Mode of child birth } \\
\hline Cesarean section & 65 & 24.0 & $0.59(0.43-0.82)$ & 0.0001 \\
\hline Spontaneous vaginal delivery & 205 & 76.0 & Reference & \\
\hline \multicolumn{5}{|l|}{ Resuscitation } \\
\hline Yes & 105 & 38.9 & $1.63(1.25-2.13)$ & $<0.001$ \\
\hline No & 165 & 61.1 & Reference & \\
\hline \multicolumn{5}{|l|}{ Provenance } \\
\hline At home & 17 & 6.3 & $0.99(0.58-1.59)$ & 0.973 \\
\hline Referred & 80 & 29.6 & $1.02(0.77-1.36)$ & 0.868 \\
\hline DLH Maternity & 173 & 64.1 & Reference & \\
\hline
\end{tabular}




\section{Discussion}

The aim of this study was to evaluate the impact of new strategies initiated in a tertiary care hospital in Douala to reduce neonatal mortality. It shows that the in-hospital neonatal mortality rate was $13.3 \%$. The causes of neonatal mortality were prematurity (37.8\%), neonatal infection (34.1\%) and perinatal asphyxia (24.4\%). Primary level of education, less than 4 antenatal visits as well as prematurity significantly increased the risk of neonatal death.

\subsection{Hospital Neonatal Mortality}

The neonatal mortality rate in our study was $13.3 \%$. This result is lower than the mortality rate of $20.3 \%$ found by Kedy Koum et al. in the same hospital in 2015 [6]. Owusu et al. also reported a higher mortality rate than our study in Ghana in 2018 [8]. Our results are similar to those of Koki Ndombo et al. in Cameroon in 2017 who had a mortality rate of $15.7 \%$ [7]. This result could be explained by the new strategies adopted especially the perinatal network in Douala. This network facilitates the transfer of newborns from one health facility to another. In addition, the systematic use of an emergency care voucher for any newborn hospitalized and the improvement in the working conditions of caregivers could explain the decline in neonatal mortality at DLH.

\subsection{Causes of Neonatal Mortality}

The main causes of neonatal mortality were prematurity (37.8\%), neonatal sepsis $(34.1 \%)$ and neonatal asphyxia $(24.4 \%)$. These results are similar to those found in most studies of neonatal mortality [6]-[11].

The high proportion of deaths linked to prematurity could be justified by predominance of very preterm babies in our sample. Indeed, newborns whose gestational age is less than 32 weeks are more likely to die due to the immaturity of most vital functions. Several studies have reported a high mortality rate in this group [11] [12] [13]. They are at risk of respiratory, infectious and hemodynamic complications. In a context of scarce resources, the Kangaroo method recommended by WHO could reduce the mortality rate of premature babies [14].

Neonatal sepsis was the second leading cause of death in our study. This result suggests the need to strengthen the screening and management of maternal infections in the 3rd trimester of pregnancy as well as hygiene protocols during labor. This result could also suggest the selection of germs resistant to the usual antibiotics. Hence the interest for each neonatal department to adapt antibiotic therapy to the local bacterial ecology, while reducing the pressure of germs' selection through validated protocols.

Neonatal asphyxia was the third leading cause of death in our study. These deaths could be explained by the inadequate monitoring of pregnancy, the circumstances of childbirth, insufficient equipment and caregivers trained to handle neonatal resuscitation in our peripheral health structures. Nakibuuka et al. in 
Uganda reported a significant reduction in neonatal mortality after 3 training sessions in neonatal resuscitation and use of the partograph in Kampala [15]. It is therefore essential to ensure continuous training in neonatal resuscitation and the adequate equipment of birth rooms.

More than half of the deaths occurred during on-call hours (between 5 p.m. and 7 a.m.). Wang et al. in Shanghai made the same observation [16]. This situation could be explained by the absence of a sufficient number of qualified caregivers during the night, resulting in a decrease in the follow-up of newborns. The strengthening of on-call teams seems to be necessary.

\subsection{Factors Associated with Neonatal Mortality}

Newborns whose mothers were in the informal sector and had a primary education had a significantly high risk of death. In an American study in California, university level was a protective factor [17]. This suggests that mothers with a low level of education have limited access to health care due to the financial means and are less aware of alarming signs.

Regarding obstetrical data, less than 4 antenatal visits and malaria during pregnancy increased the risk of neonatal death. This observation highlights the importance of high quality antenatal care for the well-being and survival of the newborn.

For newborns, cesarean section was a protective factor. This observation has also been made in California [17]. Our findings raise the question of timing and indications of cesarean section in our context assuming that this intervention should improve the prognosis of the mother and the child.

A gestational age less than 32 weeks increased the risk of death. Aguilera et al reported a high risk of death in preterm babies in Chile [18]. This is explained by the immaturity of these newborns and their high susceptibility to infections.

\subsection{Limitations of the Study}

The burden of neonatal mortality in sub Saharan Africa is well known. Many interventions are made to improve survival of newborns in Cameroon. The retrospective view of this study did not allow us to observe care practices at real time and identify any delays at different levels of intervention. However, we were able to identify the causes and factors associated with neonatal mortality in the neonatal department of this tertiary care hospital.

\section{Conclusion}

Our study found a reduction in neonatal mortality at Laquintinie Douala Hospital. Prematurity, neonatal sepsis and neonatal asphyxia remain the major causes of mortality in our context. Mothers in precarious situations, poor follow-up of antenatal care and very preterm birth are the risk factors for neonatal death. This highlights the importance of strengthening quality of care and improved training of health professionals for better survival of newborns. 


\section{Acknowledgements}

To the doctors and nurses of the neonatology department of Laquintinie Hospital in Douala.

\section{Authors' Contribution}

- Conception and design: Calixte Ida Penda, Christelle Mpah Edimo, Danielle Kedy Koum, Koki Ndombo Olivier;

- Acquisition of data: Christelle Mpah Edimo, Calixte Ida Penda, Eyoum Billè Bertrand;

- Analysis and interpretation: Calixte Ida Penda, Eyoum Billè Bertrand, Ritha Mbono Betoko;

- Drafting the article or revising: Calixte Ida Penda, Ritha Mbono Betoko, Charlotte Eposse, Essome Henri, Patricia Epée Eboumbou;

- Final approval of the version: all authors;

- Agreement to be accountable for all aspects of the work: Calixte Ida Penda, Koki Ndombo Olivier.

All authors of the manuscript have read and agreed to its content and are accountable for all aspects of the accuracy and integrity of the manuscript.

\section{Conflicts of Interest}

The authors declare no conflicts of interest regarding the publication of this paper.

\section{References}

[1] OMS (2017) 7000 Newborns Die Every Day, Despite Steady Decrease in Under-Five Mortality, New Report Says.

https://www.who.int/news-room/detail/19-10-2017-7-000-newborns-die-every-daydespite-steady-decrease-in-under-five-mortality-new-report-says

[2] Kruse, A.Y., Phuong, C.N., Ho, B.T., Stensballe, L.G., Pedersen, F.K. and Greisen, G. (2014) Identification of Important and Potentially Avoidable Risk Factors in a Prospective Audit Study of Neonatal Deaths in a Paediatric Hospital in Vietnam. Acta Paediatrica, 103, 139-144. https://doi.org/10.1111/apa.12423

[3] Lawn, J. and Kerber, K. (2006) WHO on Behalf of the Partnership for Maternal Newborn and Child Health. Opportunities for Africa's Newborns: Practical Data, Policy and Programmatic Support for Newborn Care in Africa.

https://www.who.int/pmnch/media/publications/oanfullreport.pdf

[4] UNICEF (2018) Mortalité néonatale: le monde manque à ses devoirs envers les nouveau-nés.

https://www.unicef.fr/contenu/espace-medias/mortalite-infantile-le-monde-manqu e-ses-devoirs-envers-les-nouveau-nes

[5] WHO (2015) Levels and Trends in Child Mortality 2015. http://www.who.int/maternal_child_adolescent/documents/levels_trends_child_mo $\underline{\text { rtality_2015/en/ }}$

[6] Koum, D.C., Essomba, N.E., Ngaba, G.P., Sintat, S., Ndombo, P.K. and Coppieters, Y. (2015) Morbidity and Risk Factors for Neonatal Mortality in Douala Referral Hospital. Pan African Medical Journal, 17, 258. 
[7] Ndombo, P.K., Ekei, Q.M., Tochie, J.N., Temgoua, M.N., Angong, F.T., Ntock, F.N. and Mbuagbaw, L. (2017) A Cohort Analysis of Neonatal Hospital Mortality Rate and Predictors of Neonatal Mortality in a Sub-Urban Hospital of Cameroon. Italian Journal of Pediatrics, 43, Article No. 52. https://doi.org/10.1186/s13052-017-0369-5

[8] Owusu, B.A., Lim, A., Makaje, N., Wobil, P. and Same, A. (2018) Neonatal Mortality at the Neonatal Unit: The Situation at a Teaching Hospital in Ghana. African Health Sciences, 18, 369-377. https://doi.org/10.4314/ahs.v18i2.22

[9] Kedy Koum, D. Exhenry, C., Penda, C.I., Nzima Nzima, V. and Pfister, R.E. (2014) [Neonatal Morbidity and Mortality in a Low-Resource Urban District Hospital of Douala, Cameroon]. Archives de Pédiatrie, 21, 147-156.

https://doi.org/10.1016/j.arcped.2013.11.014

[10] Mah, M.E., Chiabi, A., Tchokoteu, P.F.L., Nguefack, S., Bogne, J.B., Siyou, H., Soh, F.F., Mbonda, E. and Tchokoteu, P.F. (2014) Neonatal Mortality in a Referral Hospital in Cameroon over a Seven-Year Period: Trends, Associated Factors and Causes. African Health Sciences, 14, 517-525. https://doi.org/10.4314/ahs.v14i3.4

[11] Ekure, E.N., Ezeaka, V.C., Iroha, E.O. and Egri-Okwaji, M.T. (2005) Neonatal Mortality of Inborns in the Neonatal Unit of a Tertiary Centre in Lagos, Nigeria. Nigerian Quarterly Journal of Hospital Medicine, 15, 55-58. https://doi.org/10.4314/nqjhm.v15i2.12755

[12] Zhang, B., Dai, Y., Chen, H. and Yang, C. (2019) Neonatal Mortality in Hospitalized Chinese Population: A Meta-Analysis. Biomed Research International, 2019, Article ID: 7919501. https://doi.org/10.1155/2019/7919501

[13] Mekonnen, Y., Tensou, B., Telake, D.S., Degefie, T. and Bekele, A. (2013) Neonatal Mortality in Ethiopia: Trends and Determinants. BMC Public Health, 13, Article No. 483. https://doi.org/10.1186/1471-2458-13-483

[14] Bear, R.J. and Mellor, D.J. (2017) Kangaroo Mother Care 1: Alleviation of Physiological Problems in Premature Infants. The Journal of Perinatal Education, 26, 117-124. https://doi.org/10.1891/1058-1243.26.3.117

[15] Nakibuuka, V.K., Okong, P., Waiswa, P. and Byaruhanga, R.N. (2012) Perinatal Death Audits in a Peri-Urban Hospital in Kampala, Uganda. African Health Sciences, 12, 435-442. https://doi.org/10.4314/ahs.v12i4.6

[16] Wang, X.L., Wang, J., Yuan, L., Shi, W.J., Cao, Y. and Chen, C. (2018) Trend and Causes of Neonatal Mortality in a Level III Children's Hospital in Shanghai: A 15-Year Retrospective Study. World Journal of Pediatrics, 14, 44-51. https://doi.org/10.1007/s12519-017-0101-y

[17] Ratnasiri, A.W.G., Lakshminrusimha, S., Dieckmann, R.A., Lee, H.C., Gould, J.B., Parry, S.S., et al. (2020) Maternal and Infant Predictors of Infant Mortality in California, 2007-2015. PLoS One, 15, e0236877. https://doi.org/10.1371/journal.pone.0236877

[18] Aguilera, X., Delgado, I., Icaza, G., Apablaza, M., Villanueva, L. and Castillo-Laborde, C. (2020) Under Five and Infant Mortality in Chile (1990-2016): Trends, Disparities, and Causes of Death. PLOS ONE, 15, e0239974. https://doi.org/10.1371/journal.pone.0239974 